\title{
THE SIGNIFICANCE OF ELECTROCARDIO- GRAMS SHOWING A "SECOND POSITIVE WAVE OF QRS" IN LEAD III
}

\author{
BY \\ A. A. FITZGERALD PEEL $\dagger$ \\ (From the Electrocardiographic Department, Victoria Infirmary, Glasgow)
}

During the past two years an investigation has been made to determine whether electrocardiograms showing anomalous forms of QRS in lead III have any diagnostic or prognostic importance. Several distinct types of anomalous QRS3 have been encountered, and the findings in one of these types have already been published ("Large Q3," Peel, 1938). It is now proposed to consider a second variety in which the $\mathrm{R}$ and $\mathrm{S}$ deflections are followed by a third wave directed upwards and pointed. Katz and Slater (1935) have named this " the second positive wave of QRS3" and specify the following criteria for its recognition :

1. The standardization must show no " overshoot."

2. R3 must be a positive wave above the iso-electric line.

3. R3 must be followed by a definite S3, the amplitude of which may vary.

4. The upstroke of S3 must rise above the iso-electric level to a positive peak, and then descend either suddenly or gradually to the isoelectric level ; this peak may or may not be notched.

Katz and Slater collected 320 examples from a series of 8000 electrocardiograms and published a preliminary report on 50 of them, including post-mortem records in three cases. Clinical evidence of organic disease was present in 86 per cent., and they concluded that the abnormality should be regarded as indicative of organic myocardial disease.

Hope Gosse and Lowe (1937) found complexes of this type in $2 \cdot 2$ per cent. of all their cases, and published an analysis of 44 ; they arrived at a conclusion diametrically opposed to that of Katz and Slater : "Of this $2 \cdot 2$ per cent. the cases were almost equally divided between hearts diagnosed as clinically normal and those in which myocardial damage was considered to be present. . . . As a result of this investigation we do not find that any diagnostic importance can as yet be placed upon this variation from the average normal ventricular complex."

Although these are the only publications which deal directly with the type 
of complex in question, certain others have an indirect bearing on the subject. Katz and Slater admit any electrocardiogram in which lead III fulfils their requirements, irrespective of the presence or absence of abnormality in the remaining leads and irrespective of the breadth of the QRS complex. Some electrocardiograms which have been described as examples of right branch bundle block conform to their definition in so far as QRS3 is concerned, though it is true that Wilson's (1934) original description of what has since been termed "the common variety of right branch bundle block" fails to fulfil their second condition, as there is no initial R3. V. Deesten and Dolganos (1934), however, include some records with and some without an initial $\mathrm{R}$ in their description of "atypical branch bundle block with a favourable prognosis"; those with an initial R satisfy all of Katz and Slater's criteria. It is of interest to note that the single illustration published by Hope Gosse and Lowe has a broad QRS measuring 0.12 sec., with a broad $\mathrm{S}$ in leads I and II corresponding in time to the "second positive wave" of lead III ; it differs from Wilson's description of branch bundle block only in the presence of the initial R3.

Another article germane to the subject is by Bland and White (1931), entitled "The clinical significance of complete inversion of lead III." Admittedly the electrocardiogram illustrated shows no " second positive wave" ; it has inverted $P$ and $T$ waves, small $R$ and large $S$. It is clear, however, that the appearance of the QRS complex resulting from inversion will vary from case to case according to the deflections originally present. A complex consisting of $\mathrm{Q}$ and $\mathrm{R}$ will become $\mathrm{R}$ and $\mathrm{S}$ after inversion ; one in which the original deflections are $\mathrm{R}$ and $\mathrm{S}$ will show $\mathrm{Q}$ and $\mathrm{R}$; while inversion of an electrocardiogram with $\mathrm{Q}, \mathrm{R}$, and $\mathrm{S}$ will produce a complex consisting of $\mathrm{R}, \mathrm{S}$, and a " second positive wave."

Bland and White had 115 cases which they considered to show complete inversion of lead III. Organic disease was only present in 55 per cent. as compared with 82 per cent. of their total patients. On the other hand, 72 per cent. of those with inversion of lead III had some condition liable to produce a transverse lie of the heart, and the abnormality was often abolished by deep inspiration. They conclude that an electrocardiogram showing complete inversion of lead III is usually associated with a transverse lie of the heart and has little clinical significance. Proger (1931) described electrocardiograms similar to those discussed by Bland and White as occurring frequently in obesity. It may be recalled that Hurxthal (1933) suggested that a "large Q3 " in many instances represented an "inverted R." We have previously shown (Peel, 1938) that electrocardiograms with a large Q3 can be subdivided into two groups, one of which is closely associated with coronary disease $(\mathrm{Q} 2$ present), while the other is frequently found in obese patients and is in many cases related to a transverse lie of the heart (Q2 absent). If Hurxthal's suggestion is accepted, the findings relative to this second group are brought into line with those of Bland and White.

It seems reasonable to suggest that the discrepancy between the conclusions of Katz and Slater and those of Hope Gosse and Lowe may to some extent be explained on the assumption that electrocardiograms showing a "second positive wave" in lead III are not all identical. Some may represent branch 
bundle block, implying organic myocardial disease ; others may correspond to Bland and White's " inversion of lead III," and be associated with a transverse lie of the heart ; and there may well exist yet other types. Another possible explanation of the difference found in the two series may lie in the nature of the material from which the cases were drawn.

In dealing with the present series, we propose to use the symbol " $\mathrm{R}^{\prime}$ " for the "second positive wave of QRS", examples of which are shown in Figs. 1 and 2 . We have analysed 1200 consecutive cases from our original material
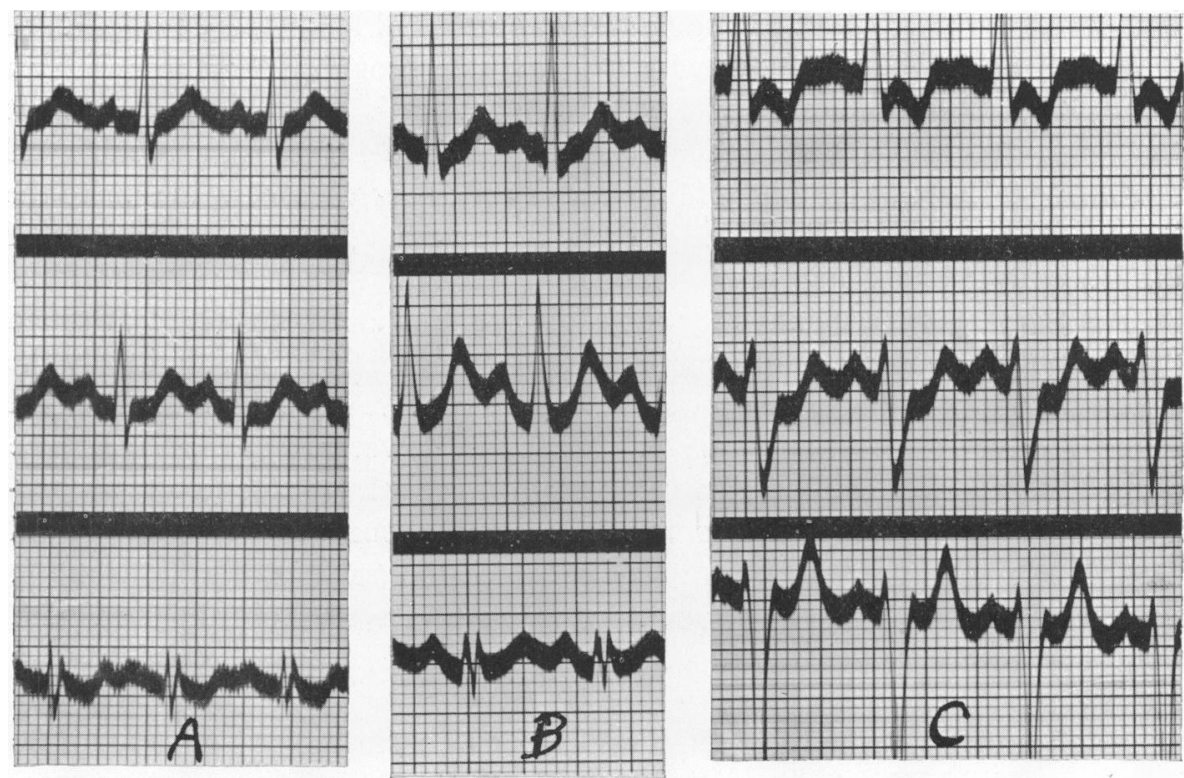

FIG. 1.-Examples of QRS3 showing a " second positive wave" and R3 exceeding $2 \mathrm{~mm}$. in height. Type associated with a high incidence of organic disease and high mortality, irrespective of the presence of other electrocardiographic abnormality.

A. Electrocardiogram otherwise normal. Male, 41, hypertensive heart disease.

B. Electrocardiogram otherwise normal. Female, 21, mitral endocarditis.

C. Electrocardiogram otherwise abnormal. Male, 59, cardio-aortic syphilis and effort angina.

so as to compare the incidence of organic disease in patients with an " $R^{\prime}$ " in lead III, with that in the total series. Next we have extracted those patients whose electrocardiograms were completely normal and compared them with those whose only electrocardiographic abnormality consisted of an " $R$ '" in lead III. We have investigated the influence of other features in the electrocardiogram in determining the diagnostic and prognostic significance of the abnormality. We have looked into the possibility of differentiating complexes with an " $R^{\prime}$ " into two or more groups which might differ in their import. Finally in those of our cases in whom serial electrocardiograms are available, we have studied the conditions under which " $R^{\prime}$ " has appeared or disappeared. 
ANALYSIS OF RESUlTS

The material from which our examples were obtained consists of 1307 patients examined during the years 1928-1933. An analysis of 1200 consecu-

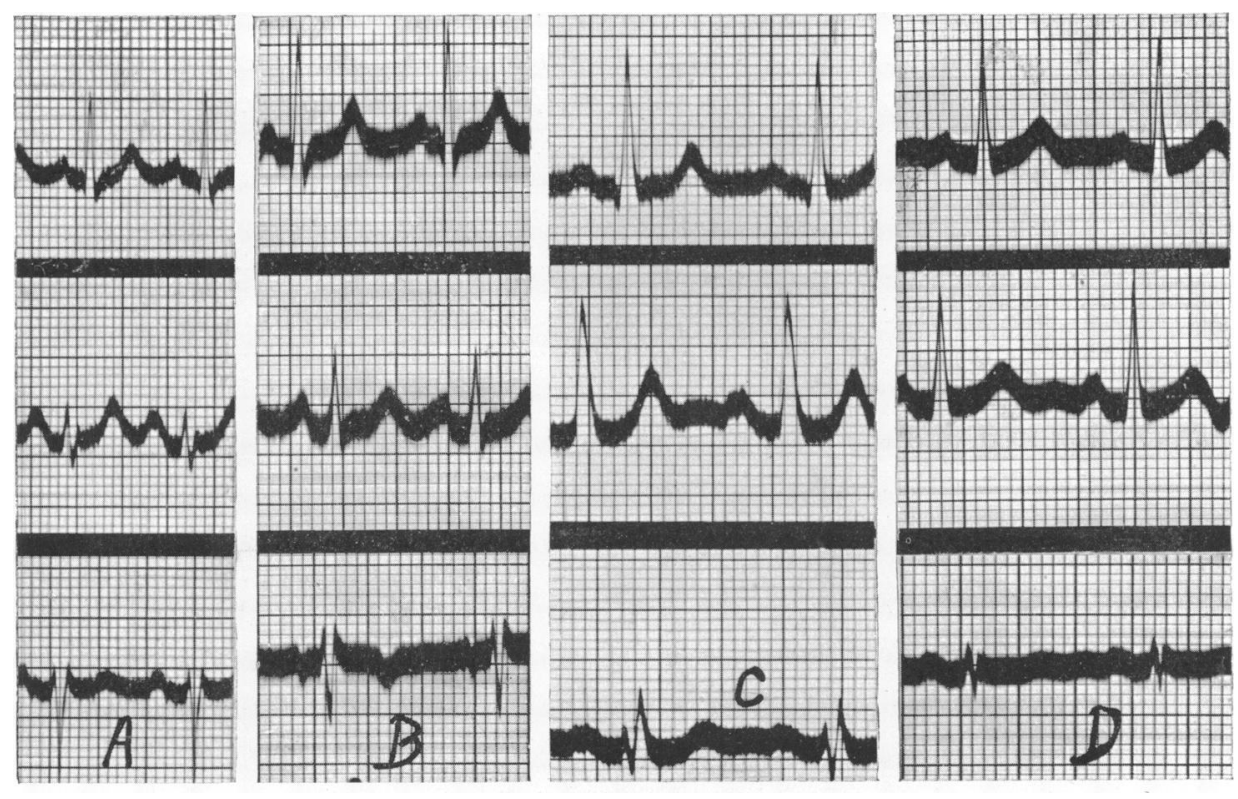

FIG. 2.-Examples of QRS3 showing a " second positive wave" and R3 small (less than $2 \mathrm{~mm}$.) Type associated with a lower incidence of organic disease and low mortality provided the electrocardiogram is otherwise normal.

A. QRS3 resembling a normal complex which has been inverted, but P3 and T3 are upright. Male, 64, no organic heart disease.

B. QRS3 resembling an inverted normal complex ; P3 and T3 also inverted-“"Complete inversion of lead III" (Bland and White, 1931). Female, 25, obese and neurotic.

C. QRS3 showing small $R$ and $S$ with large "second positive wave." A sparsely built man of 61 with a prominent abdomen.

D. QRS3 showing all three deflections small. Male, 61, effort syndrome, no organic heart disease.

tive cases showed 28 per cent. in whom no certain evidence of organic cardiovascular disease was detected clinically and 72 per cent. with such evidence. Of these, 33 per cent. had infective lesions ; 26 per cent. suffered from coronary disease, arteriosclerosis, or hypertension ; 4 per cent. had primary pulmonary disease, and 4 per cent. thyrotoxicosis ; the remaining 5 per cent. had miscellaneous conditions including myxœdema, obesity, anæmia with cardiac complications, congenital lesions, etc.

We have 62 patients in whom the electrocardiogram has at some time shown an " $\mathrm{R}^{\prime}$ " in lead III, excluding one in whom it was only noted during paroxysms of ventricular tachycardia. Organic heart disease was recognized clinically in 51 cases ( 82 per cent.), a figure which agrees closely with that given by Katz and Slater. The incidence of organic disease is somewhat higher than in the total series, and the increase is confined to cases of coronary disease, arteriosclerosis, and hypertension ; these account for 57 per cent., or more than double their 
incidence in the total material. Rheumatic lesions were less frequent (14.5 per cent. as compared with 28 per cent.), while pulmonary disease and thyrotoxicosis showed no difference.

Two patients were labelled "doubtful" and nine (14.5 per cent.) were thought to be free from organic cardiac disease at the time of examination. It is difficult to exclude heart disease with certainty in these cases. Five were below the age of 45 ; two of them had mild hyperthyroidism, one had extrasystoles, one had fainting attacks which were regarded as petit mal, and one was an obese woman with acute cholecystitis and a rapid pulse. The remaining six were over 45 ; two had extrasystoles, in one case following an acute infection and accompanied by tachycardia and impaired exercise tolerance ; on the other hand, two had a condition liable to produce a transverse lie of the heart (splenomegaly in one, diverticulosis in the other); and two suffered from a neurosis. It is significant that of the seven patients traced, three are working, a fourth is much improved, and the incapacity in one case is of nervous origin ; one died six years after examination from a cause unknown; and the last died from acute circulatory failure following cholecystectomy. These cases may be summarized by stating that organic myocardial disease was probably present but unrecognized in one, that it may have been present in another who died, and that in three with extrasystoles there was a septic focus or recent infection which may have caused temporary myocardial damage. In the remaining six myocardial disease was probably absent; two of them had a condition liable to produce a transverse lie of the heart.

Of the 62 patients with an " $R^{\prime}$ " in lead III, 45 have been traced (March 1938). Twenty-five patients have died and three are incapacitated, but in one of them the incapacity is nervous in origin. Nine have improved and eight are working.

\section{The Influence of other Electrocardiographic Features}

Many electrocardiograms with an " $\mathrm{R}$ '" in lead III show some other abnormality in addition (see Fig. 3), and these fall into two groups. The first includes findings which would be regarded as significant irrespective of the presence of " $\mathrm{R}^{\prime}$ " (e.g. RT displacement, coronary $\mathrm{T}$ wave, branch bundle block or intraventricular block, auricular flutter, and auricular fibrillation); the second includes those which would be considered of little or no importance in the absence of " $R^{\prime}$ " (e.g. abnormalities of the electric axis, slight notching of auricular or ventricular complexes, digitalis effects, inversion of P3 or T3, extrasystoles, and nodal escape).

There are 26 cases in which the electrocardiogram showed some " significant" abnormality as defined above in addition to an " $\mathrm{R}^{\prime}$ " in lead III. Organic disease was present in all, and the prognosis was extremely bad. Out of 22 patients traced, 20 are dead, one is incapacitated, and only one has improved. In the two living patients, the " $R$ '" and the other abnormality were not present simultaneously, but succeeded one another. When an " $R^{\prime}$ " and another significant abnormality were present simultaneously, all the cases traced have died (19 out of 23). 
In 36 of our patients the electrocardiogram was normal except for the presence of an " $\mathrm{R}^{\prime}$ " in lead III. For comparison with these we have collected 352 cases from the same original material in whom the electrocardiogram was
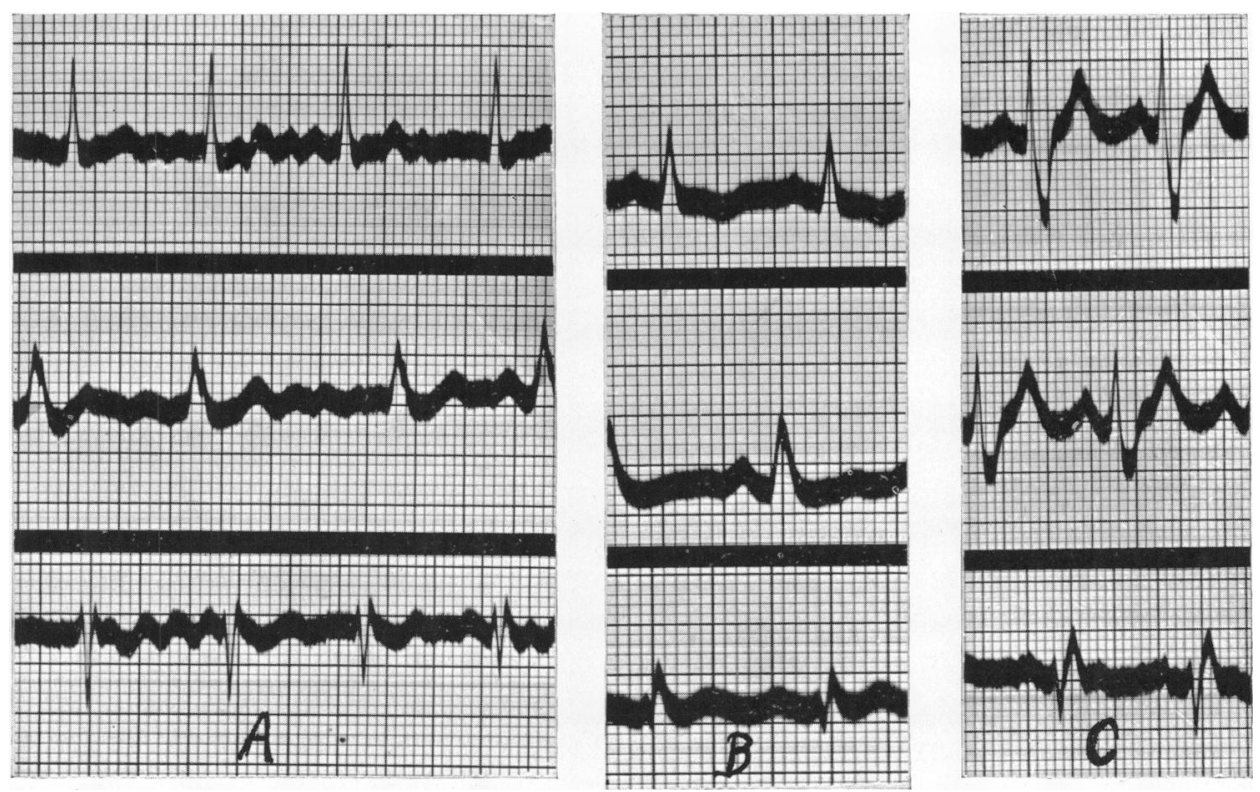

FIG. 3.-Examples of QRS3 showing a " second positive wave" and R3 small, but electrocardiogram otherwise abnormal. Type associated with high incidence of organic disease and high mortality.

A. QRS3 resembling an inverted normal complex. A sparsely built man of 59 with auricular fibrillation.

B. QRS3 with minute $R$ and $S$ and prominent " $R$ ", $T 1$ inversion. Male, 62, hypertension.

C. Wilson's type of right bundle branch block, showing in lead III a small initial $\mathrm{R}, \mathrm{S}$, and broad " $R^{\prime}$." The electrocardiogram fulfils Katz and Slater's criteria. Male, 57, with chronic coronary disease and congestive failure.

normal and showed no " $R^{\prime}$ " in lead III. Organic heart disease is very much more frequent in those with an " $\mathrm{R}^{\prime} 3$ " than in those without (70 per cent. as compared with 43 per cent.), and the increase is accounted for entirely by cases of coronary disease, of arteriosclerosis, or of hypertension ; these comprised 42 per cent. as compared with 8 per cent. in patients with normal electrocardiograms. Rheumatic lesions were slightly less frequent, while the incidence of other forms of heart disease was approximately the same.

We have no follow-up figures available for the patients whose electrocardiograms were completely normal. Of the 36 whose only abnormality was an " $\mathrm{R}^{\prime}$ " in lead III, 23 have been traced. Five are dead and two are incapacitated ; eight have improved and eight are able for work. The prognosis is very much better than when the electrocardiogram shows some "significant" abnormality in addition to an " $\mathrm{R}^{\prime}$ " in lead III.

We have attempted to determine whether there are any electrocardiographic features which will enable the diagnostic or prognostic value of an " $R$ ' " to be 
gauged when no other "significant" abnormality is present. If a relationship exists between some of these cases and Wilson's type of bundle branch block, it might be thought that the presence or absence of an S in lead I would help in their differentiation. This is not the case, there being no appreciable difference between the cases with and those without an S1. Having previously shown the importance of Q2 in assessing the diagnostic value of electrocardiograms with a "large Q3," it was thought that Q2 might also help in evaluating those with an " $R$ '" in lead III. There is, however, no significant difference in the incidence of organic lesions, the incidence of coronary disease, the mortality rate, or the recovery rate, when groups with and without a Q2 are compared.

There is evidence that the character of QRS3 itself may be of diagnostic and prognostic importance. Katz and Slater's definition is compatible with wide variations in the actual form of the complex; any one deflection ( $R, S$, or " $R$ ' ") may be prominent with the other two small ; any two may be prominent with the third small ; all three may be large, or all three may be small. Thus there are eight possible subgroups, each of which we have investigated individually. It was found that in every group with a prominent initial $\mathrm{R}$ (exceeding $2 \mathrm{~mm}$. in height) organic disease was always present and the mortality was high -75 per cent. for the whole group and 50 per cent. even when " $R$ '," was the only significant abnormality in the electrocardiogram (see Fig. 1). On the other hand in every group with a small initial $\mathrm{R}$ (less than $2 \mathrm{~mm}$. in height) (see Fig. 2) there were a number of patients who were thought to be free from organic disease, and the mortality rate was much lower- 45 per cent. for the whole group and only 12 per cent. when the electrocardiogram was otherwise normal. All eight patients who recovered working capacity and seven of the remaining nine who improved belong to the group with a small initial $\mathrm{R}$ and no other abnormality in the electrocardiogram.

This finding is of considerable importance in view of Bland and White's conclusions regarding " total inversion of lead III" ; for in one of the groups defined above, namely, that with a small $R$, large $S$, and small " $R$ '," the complex exactly resembles a normal QRS which has been inverted ; P3 and T3 were only inverted in about half the cases. If it is justifiable to regard these as “ inverted QRS complexes," the significance of the large initial $\mathrm{R}$ in the other group can be explained on the assumption that it represents inversion of a complex which originally showed a large Q3, a suggestion made by Hurxthal in 1933.

The electric axis is not strictly comparable with the height of $\mathrm{R}$ in lead III for some cases with a " prominent" initial R3 show left axial deviation, while some with a small $\mathrm{R} 3$ have a normal axis. When an " $\mathrm{R}$ " " in lead III is the only abnormality in the electrocardiogram, there is little difference between those with a normal axis and those with left axial deviation, either in the incidence of organic disease, the mortality rate, or the recovery rate. On the other hand, left axial deviation is more common than a normal axis when other significant abnormalities are present in the electrocardiogram; since the mortality rate is very much higher in the latter circumstances, it follows that 
the prognosis is worse with left axial deviation than with a normal axis, when the remaining features of the electrocardiogram are not taken into account.

As was found to be the case with electrocardiograms showing a large Q3, the breadth of QRS is an extremely important prognostic feature in those with an " $R$ '" in lead III. The ultimate fate of 45 patients traced is compared in the table with the breadth of their QRS complexes. The mortality rate rises steadily and the recovery rate falls steadily as the breadth of QRS increases ; and there is such a close parallel between this series and the "large Q3" series previously published that repetition of the latter figures seems justifiable for comparison.

Even when electrocardiograms which show other abnormalities are excluded, the breadth of QRS is still important for prognosis. This procedure considerably reduces the number with a broad QRS, as it cuts out all cases with bundle branch block or intraventricular block. We have traced 23 patients who had an " $\mathrm{R}$ " " in lead III but no other significant abnormality. In seven, $\mathrm{QRS}$ was less than $0.08 \mathrm{sec}$. ; six are either improved or working and one is dead. In 16, QRS measured 0.08 or more ; four are dead and two are incapacitated, six have improved and four are working.

TABLE I

The INFLUENCE OF THE BREADTh OF QRS

\begin{tabular}{|c|c|c|c|c|c|c|}
\hline & & & $\begin{array}{l}\text { CASES } \\
\text { TRACED }\end{array}$ & $\begin{array}{c}\text { DEAD, } \\
\text { PER CENT. }\end{array}$ & $\begin{array}{l}\text { INCAPACITATED, } \\
\text { PER CENT. }\end{array}$ & $\begin{array}{l}\text { IMPROVED OR WELL, } \\
\text { PER CENT. }\end{array}$ \\
\hline $\begin{array}{l}\text { QRS below } 0.08 \\
\text { Large Q3 } \because \\
\text { Present series }\end{array}$ & $\begin{array}{l}\cdots \\
\cdots\end{array}$ & $\begin{array}{l}\cdots \\
\cdots\end{array}$ & $\begin{array}{r}13 \\
9\end{array}$ & $\begin{array}{l}23 \\
22\end{array}$ & $\begin{array}{r}15 \\
0\end{array}$ & $\begin{array}{l}62 \\
78 \text { (44 working) }\end{array}$ \\
\hline Total & .. & $\ldots$ & 22 & 22 & 9 & 68 \\
\hline $\begin{array}{c}\text { QRS }=0.08 \text { sec. } \\
\text { Large Q3 } \ldots \\
\text { Present series }\end{array}$ & $\begin{array}{l}\cdots \\
\cdots\end{array}$ & $\begin{array}{l}\cdots \\
\cdots\end{array}$ & $\begin{array}{l}14 \\
18\end{array}$ & $\begin{array}{l}43 \\
55\end{array}$ & $\begin{array}{l}28 \\
11\end{array}$ & $\begin{array}{l}28 \\
33 \text { (11 working) }\end{array}$ \\
\hline Total & . & . & 32 & 50 & 18 & 31 \\
\hline $\begin{array}{l}\text { QRS above 0.08 } \\
\text { Large Q3 } \\
\text { Present series }\end{array}$ & $\begin{array}{l}\cdots \\
\ldots\end{array}$ & $\begin{array}{l}. \\
.\end{array}$ & $\begin{array}{l}15 \\
18\end{array}$ & $\begin{array}{l}73 \\
72\end{array}$ & $\begin{array}{r}13 \\
6\end{array}$ & $\begin{array}{l}13 \\
22 \text { (11 working) }\end{array}$ \\
\hline Total & .. & .. & 33 & 72 & 9 & 18 \\
\hline
\end{tabular}

The Appearance or Disappearance of an " $R$ '" in Lead III

In four of our cases an " $R^{\prime}$ " has appeared in lead III while the patient was under observation. They are as follows :

1. An obese woman of 36 with acute cholecystitis ; the development of " $R^{\prime}$ " coincided with the onset of fatal circulatory failure immediately after operation. 
2. A man of 30 with syphilitic aortitis, angina of effort, and gross RT depression in all leads of the electrocardiogram. " $\mathrm{R}$ " " appeared three weeks later, when RT had returned to the iso-electric level. A few hours after this record was obtained, he died suddenly. Post-mortem examination showed œdematous swelling of syphilitic plaques, producing almost complete occlusion of both coronary orifices, and the right circumflex branch contained a fresh thrombus; microscopic examination showed an interstitial myocarditis of older date.

3. A stout woman of 54 with hypertension and congestive failure had a falling blood pressure along with the electrocardiographic changes of coronary disease. At one stage there was an " $\mathrm{R}$ '" in lead III. Later the initial $\mathrm{R}$ disappeared, leaving $S$ and " $\mathrm{R}^{\prime}$ " only, accompanied by inversion of $T 1$. She improved temporarily, but died from congestive failure three years later.

4. A man of 54 with hypertension developed auricular flutter during an attack of lobar pneumonia. " $\mathrm{R}$ " " appeared when the normal rhythm recurred spontaneously a few days after the crisis. Seven years later auricular fibrillation was present and " $R$ '3" had disappeared ; despite the fibrillation his capacity for effort was better than when he was convalescent from the pneumonia.

TABLE II

Incidence of Heart Disease Expressed as Percentages, and FOLLOW-UP RESULTS

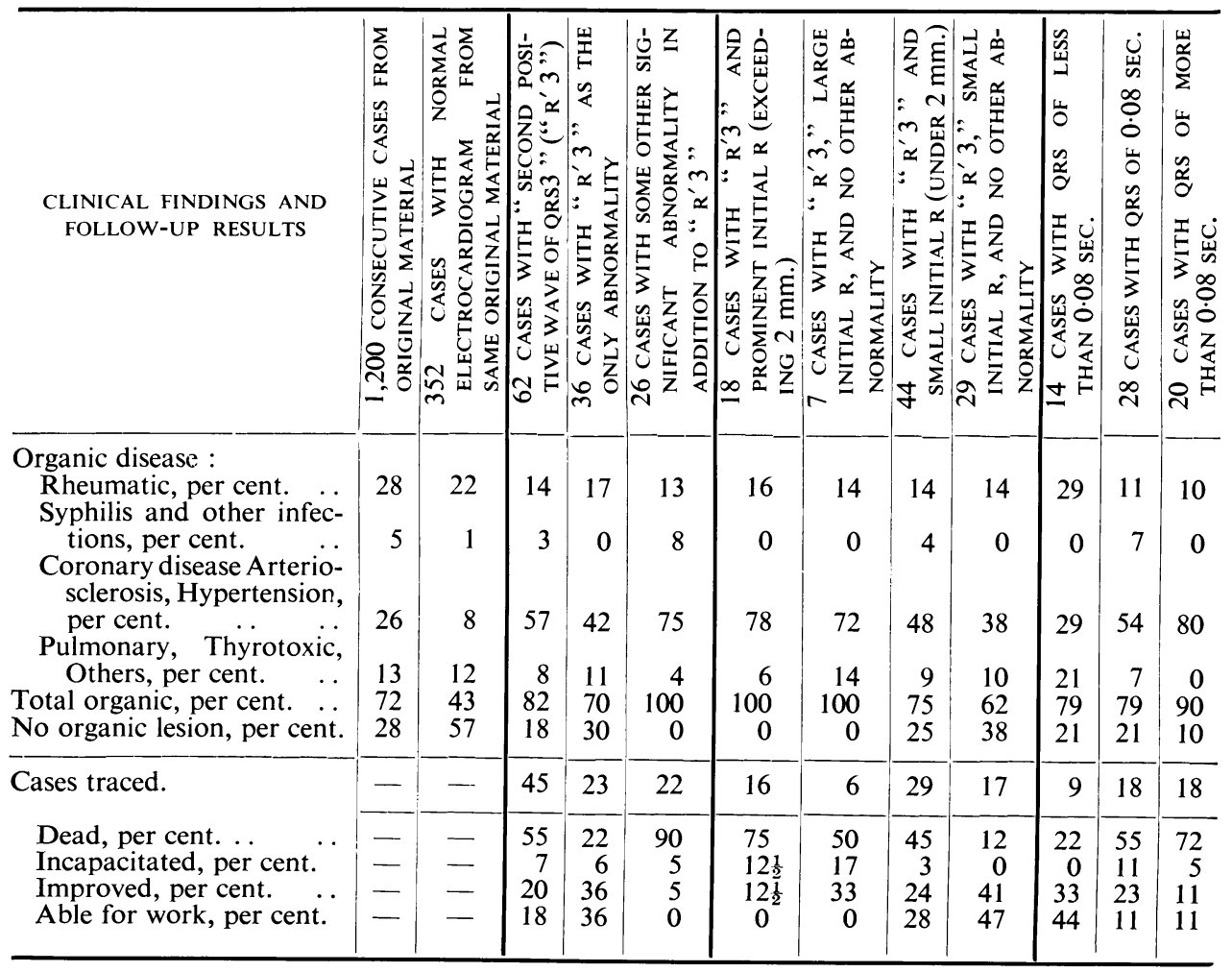


In each of these four cases there are good grounds for associating the appearance of an " $\mathrm{R}$ " " in lead III with the existence of an active pathological process affecting the myocardium.

In eight of our cases an " $\mathrm{R}^{\prime}$ " has disappeared at a later date. Its disappearance has only occurred while under observation in three cases. Two were cases of severe rheumatic carditis in which " $\mathrm{R}^{\prime}$ " was present during the acute stage and vanished as convalescence became established; one of the patients made a good recovery, but the other was left with an adherent pericardium and died three years later. The third case was one of coronary disease with congestive failure, who became slowly worse and died two weeks after " $\mathrm{R}^{\prime}$ " had gone ; this is the only case in which its disappearance was not associated with at least temporary improvement. In the remaining five cases, the patient's capacity for effort was improved when on re-examination some years later " $R^{\prime}$ " was no longer present.

\section{SUMmARY AND CONCLUSIONS}

1. Organic heart disease is more common in patients whose electrocardiograms show a "second positive wave of QRS3" than in the material from which these cases were collected ( 82 against 72 per cent.). Many of these electrocardiograms show some other significant abnormality, in which case organic disease is always present, and the mortality since 1928-1933 has been 90 per cent.

2. Organic lesions are much more frequent in patients whose sole electrocardiographic abnormality consists of a " second positive wave of QRS3" than in patients whose electrocardiograms are completely normal (70 per cent. against 43 per cent.). The increase is due to a greater number with coronary disease, hypertension, or arteriosclerosis (42 per cent. against 8 per cent.).

3. Where it has been possible to fix the time of appearance of the "second positive wave of QRS3," this has occurred when an active pathological process was affecting the myocardium. In seven out of eight cases in which it ultimately disappeared, the patient's capacity for effort improved, at least temporarily.

4. When a "second positive wave of QRS3" is the only electrocardiographic abnormality, the shape of the complex is important for diagnosis and prognosis, and its breadth gives further assistance in prognosis.

5. As regards the shape of the complex, the height of the initial $R$ is the determining factor. When this was a prominent deflection exceeding $2 \mathrm{~mm}$. in height, organic disease was always present ; and the mortality in cases with an otherwise normal electrocardiogram was 50 per cent. When the initial $\mathrm{R}$ was a small deflection of less than $2 \mathrm{~mm}$. in height the incidence of recognizable organic disease was only 62 per cent. and the mortality in cases with an otherwise normal electrocardiogram was only 12 per cent.

6. The breadth of QRS gives little help in diagnosis, but is of great importance in prognosis. The mortality rises steadily from 22 per cent. with a QRS below $0.08 \mathrm{sec}$., to 55 per cent. at $0.08 \mathrm{sec}$., and to 72 per cent. above $0.08 \mathrm{sec}$. 
These mortality figures are almost identical with those found in dealing with another series of electrocardiograms where the abnormality was a "large Q3." The significance of the breadth of QRS therefore appears to be independent of the nature of any abnormality which may be present.

I am greatly indebted to Miss A. Miller, almoner at the Victoria Infirmary, for her valuable help in tracing patients ; to Drs. G. J. Wilson and A. E. S. Melville with the staff of the X-ray department ; to Dr. John Anderson, pathologist ; to the members of the medical and surgical staff ; and to the numerous practitioners who have kindly furnished information regarding their patients.

\section{REFERENCES}

Bland, E. F., and White, P. D. (1931). Amer. Heart J., 6, 333.

Deesten, H. T. von, and Dolganos, M. (1934). Amer. J. med. Sci., 188, 231.

Gosse, A. H., and Lowe, T. E. (1937). Quart. J. Med. (new series), 6, 301.

Hurxthal, L. M. (1933). Amer. Heart J., 9, 238.

Katz, S. M., and Slater, S. R. (1935). Arch. intern. Med., 55, 86.

Peel, A. A. F. (1938). Glasg. Med. J., 129, 53.

Proger, S. H. (1931). Arch. intern. Med., 47, 64.

Wilson, F. N., Johnston, F. D., McLeod, A. G., Hill, I. G. W., and Barker, P. S. (1934). Amer. Heart J., 9, 459. 